\title{
Estimation of Genetic Parameters for Milk Fat Depression in Dairy Cattle
}

\author{
M. P. L. Calus, ${ }^{1,2}$ M. J. Carrick, ${ }^{1}$ R. F. Veerkamp, ${ }^{2}$ and M. E. Goddard ${ }^{1,3}$ \\ ${ }^{1}$ Department of Primary Industries Research Victoria \\ Attwood, Victoria, 3049, Australia \\ ${ }^{2}$ Animal Sciences Group, Division Animal Resources Development \\ PO Box 65, 8200 AB Lelystad, The Netherlands \\ ${ }^{3}$ Institute of Land and Food Resources, University of Melbourne \\ Parkville, Victoria, 3052, Australia
}

\begin{abstract}
The objective of this study was to apply reaction norm models to milk recording data to investigate genetic variation in and environmental sensitivity of susceptibility to milk fat depression (MFD). Data comprised 556,276 test-day records of 80,493 heifers in 1043 herds. Breeding values and genetic variances for fat percentage and fat yield were estimated by applying random regression models to average herd-test-day fat percentage. Genetic and permanent environmental correlations between fat yield expressed in different environments ranged, respectively, from 0.83 to 1.00 and from 0.29 to 1.00 . Genetic and permanent environmental correlations between fat percentage expressed in different environments ranged, respectively, from 0.87 to 1.00 and from -0.05 to 0.99 . Two traits were defined for MFD. The first trait reflected variation of milk fat percentage of animals within lactation after correction for year-season, herd-test-day, age-at-calving, and stageof-lactation. This trait had an estimated heritability of about 5\% and a genetic correlation between the fifth and 95th percentile of the data of 0.50 . The second trait reflected the deviation of an animal's fat percentage on a test-day from its expected fat percentage based on fat percentage on the first test-day. This trait had an estimated heritability of about $4 \%$ and a genetic correlation between the fifth and 95th percentile of the data of 0.43 . The correlation between estimated breeding values of sires for the $2 \mathrm{MFD}$ traits was -0.3. Our results suggest that genetic variation in susceptibility to MFD is present and that selection for reduced susceptibility to MFD is possible.
\end{abstract}

(Key words: milk fat depression, acidosis, environmental sensitivity, reaction norm model)

Abbreviation key: AHTDF\% = average herd-test-day fat percentage, $\mathbf{B V M}=$ bivariate repeatability model,

Received August 25, 2004.

Accepted November 17, 2004.

Corresponding author: M. P. L. Calus; e-mail: mario.calus@wur.nl.
MF\% = milk fat percentage, $\mathbf{M F D}=$ milk fat depression, MFDLAC $=$ milk fat depression trait defined on a lactation level, MFDTD = milk fat depression trait defined on a test-day level, RRM = random regression model.

\section{INTRODUCTION}

Feeding diets with a high proportion of concentrate and low fiber to dairy cattle can result in decreased $\mathrm{pH}$ in the rumen (Nocek, 1997; Kennelly et al., 1999; Bargo et al., 2003) leading to depression of milk fat percentage (milk fat depression, MFD) (Stockdale et al., 1987; Sutton, 1989; Bargo et al., 2003), and, in some cases, to (subclinical) acidosis (Nocek, 1997; Bargo et al., 2003). Although the exact mechanism is not known, one of the proposed theories is that milk fat synthesis is inhibited because of metabolic changes in the rumen (e.g., Griinari et al., 1998). A decrease in milk fat percentage (MF\%) can directly lead to financial loss if the milk price depends on MF\%. In addition, it has been shown that a strong decrease in MF\% in early lactation is related to a larger and longer lasting negative energy balance (De Vries and Veerkamp, 2000) and lower first service conception (Loeffler et al., 1999). Subclinical acidosis is associated with several problems such as reduced feed intake, lower efficiency of milk production, and laminitis (Nocek, 1997). Clinical acidosis results in very sick cows.

Occurrence of MFD can be observed by monitoring changes in MF\% or fat-to-protein ratio, as protein percentage is reported to be either unchanged or enhanced during MFD (Bargo et al., 2003). Additional symptoms for subclinical acidosis are reduced feed intake, BW loss, diarrhea, and lameness (Nocek, 1997). Gröhn et al. (1989) reported that acidosis mostly occurs in early lactation. Prevention of MFD and acidosis can be achieved by feeding a balanced diet or by adding a buffer to the diet (Kennelly et al., 1999). Feeding balanced diets might be impossible in pasture-based systems where diets depend on the seasonal supply of grass and where concentrate is used to compensate for temporary low availability of grass rather than as a permanent 
component of the diet. In situations where concentrates are used as a structural supplement to pasture, occurrence of MFD is still reported (Bargo et al., 2002, 2003) indicating that not only temporary, but also continuously high proportions of concentrate in the diet can cause MFD.

Although most experiments that challenged animals to express MFD reported a depression in MF\%, some reported a depression of fat yield (Gaynor et al., 1994; Griinari et al., 1998), and others found no effect on fat yield (Bargo et al., 2002). This is in agreement with the general observation that diets with a high proportion of concentrates or low fiber may cause depressed MF\%, while milk yield is either unchanged or enhanced (Bargo et al., 2003). A question from a breeder's point of view is whether susceptibility to MFD is correlated to breeding values for fat yield and $\mathrm{MF} \%$, and also to breeding values for health and fertility.

Although much is known about causal relationships between composition of the diet and MFD, little is known about differences in MFD between genotypes (i.e., genetic variance of MFD) or differences in responses of genotypes to different diets (i.e., genotype $\times$ environment interaction of MFD). To estimate genetic variance and genotype $\times$ environment interaction, a large number of records are needed, whereas MFD is typically examined in feeding experiments, where responses are measured within small treatment groups (Stockdale et al., 1987; Bargo et al., 2002). However, as occurrence of MFD can be observed as a change in $\mathrm{MF} \%$, it should be possible to define MFD on an individual and an environmental level using test-day records for $\mathrm{MF} \%$. This practice would enable the use of large data sets available from milk recording to investigate occurrence of MFD on an environmental and a genetic level.

Random regression models ( $\mathbf{R R M}$ ) modeling reaction norms (Veerkamp and Goddard, 1998; Kolmodin et al., 2002; Calus and Veerkamp, 2003; Hayes et al., 2003) can be used to investigate environmental sensitivity of $\mathrm{EBV}$ and genetic variances. In an RRM, an animal's breeding value for a particular trait is modeled as a function of a particular environmental variable. Thus, we need to choose a trait measured on each individual cow and an environmental indicator variable. Because MFD is a depression in MF\%, it seems logical to choose MF\% as the trait and average herd-test-day MF\% (AHTDF\%) as the environmental indicator. Then a cow that was highly susceptible to MFD would be expected to have a very low MF\% on days when AHTDF\% was low and, perhaps, a normal MF\% on days when AHTDF\% was high. However, other factors, such as management, stage of lactation, or frequency of milking affect MF\% as well as MFD. For instance, low MF\% could reflect an increase in milk volume due to good nutrition (Bargo et al., 2003), or high MF\% a decrease in milk volume due to mastitis (Windig et al., accepted). Therefore, we have tested a range of response traits to determine which might be the best at identifying bulls whose daughters are susceptible to MFD. In addition to the use of MF\% and fat yield as response traits of MFD, we investigated other indicators based on the pattern of MF\% across test-days within lactation.

The objective of this study was to investigate genetic variation in and environmental sensitivity of susceptibility to MFD, affecting MF\% and fat yield, from milk recording data using reaction norm models.

\section{MATERIALS AND METHODS}

\section{Data}

The original data set was extracted from the Australian Dairy Herd Improvement Scheme. Initial edits of the data were described by Hayes et al. (2003) and included deleting herd-test-days with fewer than 20 heifers. Additionally, herd-test-days with average MF\% above $5.5 \%$ were deleted. The final data set for $\mathrm{MF} \%$ and fat yield contained 16,344 herd-test-days comprising 556,276 test-day records of 80,493 Holstein-Friesian heifers in 1043 herds. The final data set for the MFD trait defined on a lactation level (MFDLAC; see below) contained 3032 herd-year-season subclasses comprising 68,907 Holstein-Friesian heifers in 960 herds, after deleting heifers with fewer than 5 test-day records, herd-year-season subclasses with fewer than 5 heifers, and sires with fewer than 5 daughters in the data. The final data set for the MFD trait defined on a test-day level (MFDTD; see below) contained 14,241 herd-testdays comprising 484,219 records of 78,256 HolsteinFriesian heifers in 1021 herds, after deleting herd-testdays with $<5$ heifers and deleting sires with $<5$ daughters in the data. The relationship matrix contained 6170 animals, of which 1539 were sires with daughters in the data.

\section{Definition of Traits and Environment}

Traits for MFD. As well as fat yield and MF\%, 2 other traits were derived from the pattern of MF\% across test-days. The lactation curve for $\mathrm{MF} \%$ of an animal affected by MFD will fall below the normal lactation curve. Based on deviation of a lactation curve for MF\% from a "nonaffected" lactation curve, MFD can be divided into 2 dimensions: magnitude and duration. Two traits to reflect MFD were defined: one on a lactation level (MFDLAC) and one on a test-day level (MFDTD). The MFDLAC trait was defined as the standard deviation of residual test-day $\mathrm{MF} \%$ of a heifer. 
Residual MF\% were calculated using a model with fixed effects correcting for year-season, herd-test-day, and a third-order fixed regression on age at calving and an eighth-order fixed regression on DIM. This model yielded residuals for MF\% for each test-day record. The MFDLAC was calculated for each heifer with at least 6 test-days as the standard deviation of residual MF\% across test-days. Animals with high susceptibility to MFD are more likely to have one or more test-days with reduced $\mathrm{MF} \%$, resulting in a higher variation of $\mathrm{MF} \%$ during the lactation and therefore a higher value for MFDLAC than animals with low susceptibility to MFD.

Dalley (2002) defined MFD on a herd level as a decline in MF\% of more than $0.4 \%$ in $10 \mathrm{~d}$. Following Dalley (2002), we adopted the minimum value of the decline of $0.4 \%$ to define MFD on an individual level. The MFDTD trait was defined for all heifers with at least 2 test-day records and was based on the difference between MF\% on the first test-day and all subsequent test-days. Individual test-day records for MF\% were corrected for age at calving and DIM using smoothing splines in ASREML (Gilmour et al., 2002). From all second and later test-day records for $\mathrm{MF} \%$ of each heifer, the $\mathrm{MF} \%$ from its first test-day was subtracted. Based on the obtained difference on test-day $i$ ( $\Delta$ fat $\left.\%_{\mathrm{t}=\mathrm{i}, \mathrm{t}=1}\right)$, MFDTD was defined as follows:

$$
\begin{gathered}
\text { If } \Delta \text { fat } \%_{\mathrm{t}=\mathrm{i}, \mathrm{t}=1}<-0.4 \% \\
\text { Then: } \operatorname{MFDTD}=\Delta \text { fat } \%_{\mathrm{t}=\mathrm{i}, \mathrm{t}=1}+0.4 \\
\text { Otherwise: } \mathrm{MFDTD}=0 .
\end{gathered}
$$

This resulted in a continuously distributed trait with a maximum value of zero. Animals with high susceptibility to MFD were expected to have a lower value for MFDTD than animals with low susceptibility to MFD.

Definition of environment. Individual test-day milk, fat and protein yields, corrected for age at calving and DIM using cubic splines in ASREML (Gilmour et al., 2002), were used to calculate herd-test-day averages for fat yield, MF\%, and fat-to-protein ratio. The obtained herd-test-day averages were used to calculate differences between pairs of consecutive herd-test-days that were less than $70 \mathrm{~d}$ apart. Correlations among averages of herd-test-days were calculated to determine relationships among them.

\section{Estimation of Variance Components for Fat Percentage and Fat Yield}

Variance components for fat yield and $\mathrm{MF} \%$ were estimated using an RRM. Variance components for fat yield were also estimated using a bivariate repeatability model (BVM), to compare with results of the RRM.
Therefore, the data were divided into 10 subsets based on increasing AHTDF\%, and the BVM was applied to all possible pairs of subsets of the data. The RRM contained the same effects as the one applied by Hayes et al. (2003), although heterogeneous residual variances were included in our model. The BVM and RRM included fixed effects for mean of the trait, herd-test-day, year-season subclasses, and fixed polynomial regressions for age at calving and DIM. A fixed polynomial regression was applied to DIM with an arbitrary order of 8 to account for the average lactation curve. The BVM included correlated random effects for sire and cow in both environments, to account for genetic and permanent environment effects respectively. The RRM included random regressions for both sire and cow on AHTDF\%. In both the BVM and the RRM, a separate residual variance was estimated for each subset of the data. The general model was:

$$
\begin{gathered}
Y_{i j k l m}=\mu+H T D_{i}+Y S_{j}+\sum_{n=1}^{3} A_{n} x_{n} \\
+\sum_{o=1}^{8} D_{o} Z_{o}+\operatorname{sire}_{\mathrm{k}}+\text { cow }_{\mathrm{l}}+\mathrm{E}_{\mathrm{ijklm}}
\end{gathered}
$$

where $Y_{i j k l m}$ is the phenotypic performance of heifer $l$, $\mu$ is the average performance over all animals, $H T D_{i}$ is a fixed effect for herd-test-day $i, Y S_{j}$ is a fixed effect for year season (defined from January to June and July to December for each year) $j, A_{n}$ is coefficient $n$ of a third order fixed regression on age-at-calving, $x_{n}$ is the $n$th order polynomial corresponding to age at calving, $D_{o}$ is coefficient o of an eighth-order fixed regression on DIM, $Z_{o}$ is the oth order polynomial corresponding to DIM, sire $_{k}$ is a random sire effect for sire $k, c o w_{l}$ is a random within-sire genetic plus permanent environmental effect for heifer $l$, and $E_{i j k l m}$ is the residual effect of heifer $l$ in group of environments $m(m=1,2, \ldots, 10)$.

In the BVM, all fixed effects other than HTD and all random effects were estimated for both environments. In the RRM, all fixed effects were fitted for all environments together. Sire and cow effects were fitted as random regressions on orthogonal polynomials. We chose Legendre polynomials following the practice of Kirkpatrick et al. (1990). The orders of the random regressions for sire and cow effects were assumed equal and were increased until the highest significant order was reached based on the likelihood ratio test. In both the BVM and RRM, the residual covariance between environments was assumed zero.

\section{Estimation of Variance Components for MFD Traits}

The trait MFDTD was analyzed with the RRM as described for MF\% and fat yield, with random regres- 
sions for sire and cow on AHTDF\%. For the trait MFDLAC, a comparable RRM was applied. This trait was however defined on a lactation level and therefore the model was simplified to:

$$
Y_{i k l m}=\mu+H Y S_{i}+\sum_{n=1}^{3} A_{n} x_{n}+\operatorname{sire}_{\mathrm{k}}+\mathrm{E}_{\mathrm{iklm}}
$$

where $Y_{i k l m}$ is the phenotypic performance for MFDLAC of heifer $l, \mu$ is the average performance over all animals, $H Y S_{i}$ is a fixed effect for herd-year-season subclass (defined from January till June and July till December for each herd-year) $i, A_{n}$ is coefficient $n$ of a third-order fixed regression on age at calving, $x_{n}$ is the $n$th order polynomial corresponding to age at calving, sire $_{k}$ is a random sire effect for sire $k$, and $E_{i k l m}$ is the residual effect of heifer $l$ in group of environments $m$ $(m=1,2, \ldots, 5)$.

The random effect for sire, $\left(\operatorname{sire}_{k}\right)$ was a random regression on an average value for AHTDF\% during the lactation of an animal. This average was calculated for each heifer as the average of the values for AHTDF\% of the test-days during which the heifer had records.

\section{Calculation of Parameters from Estimated Variance Components in Different Environments}

Both models estimated variances and covariances for cow, reflecting the within-sire genetic plus permanent environmental (co)variance. Estimated permanent environmental (co)variances for both models were obtained by subtracting 3 times the estimated sire (co)variance from the estimated (co)variance for cow.

The BVM was applied to all 45 pairs of subsets of the data for fat yield, to estimate genetic and permanent environmental correlations between fat yield expressed in all subsets of the data. Hence, 9 estimates for each estimated variance component and its standard error were obtained and averaged to get final estimates. The RRM estimated sire and cow (co)variances as function of the environment, which were used to derive estimated genetic and permanent environmental (co)variances of the RRM.

The heritability in an environment was calculated as 4 times the estimated sire variance, divided by the sum of the sire, cow, and residual variance. For the trait MFDLAC, the heritability in an environment was calculated as 4 times the estimated sire variance, divided by the sum of the sire and residual variance. For the trait MFDTD, the repeatability in an environment was calculated as the sum of the sire and cow variance, divided by the sum of the sire, cow and residual variance.

\section{RESULTS}

\section{Phenotypic Levels of MFD}

Means, standard deviations, and the ranges of herdtest-day averages and differences between averages of consecutive herd-test-days for fat yield, MF\%, and fatto-protein ratio are shown in Table 1 . The average herdtest-day MF\% ranged from 2.18 to $5.48 \%$ and the change in average MF\% from one to the next herd-testday ranged from -1.82 to $1.53 \%$. Correlations between herd-test-day averages, calculated from 16,344 herdtest-days, were $0.03(\mathrm{SE}=0.01)$ between fat yield and $\mathrm{MF} \%,-0.12(\mathrm{SE}=0.01)$ between fat yield and fat-toprotein ratio, and $0.82(\mathrm{SE}=0.00)$ between average $\mathrm{MF} \%$ and fat-to-protein ratio.

The value for the heifers for the trait MFDLAC ranged from 0.00 to 1.43 , with an average of 0.28 . The average value for MFDLAC within herd-year-season subclasses ranged from 0.03 to 0.31 . The average value for MFDLAC within herd ranged from 0.04 to 0.21 .

The values for MFDTD ranged from -3.4 to $0 \%$, with an average of $-0.1 \%$. Based on the trait MFDTD, $44.9 \%$ of the heifers had one or more affected test-days resulting in $22.1 \%$ of all records being affected by MFD. In $93.7 \%$ of the herd-test-days, one or more affected heifers were identified. The percentage of affected heifers based on MFDTD decreased with increasing days in milking (Figure 1).

\section{Estimated Variance Components for Fat Yield}

Estimated genetic variances based on 556,276 testday records for the BVM and the RRM with environment defined as AHTDF\% are shown in Figure 2. Estimated genetic variances from the BVM are given with a range of their standard errors (Figure 2). The quadratic RRM was the highest significant order (a cubic order did not converge). In the range of environments where most animals were situated (i.e., fifth percentile of the data was $3.23 \%$ and 95 th percentile was $4.43 \%$ ), the sire variance of the linear and quadratic RRM was almost the same. Estimated heritabilities and genetic and permanent environmental correlations between the different subsets of the data estimated with the BVM (results not shown) and quadratic RRM (Table 2) were comparable. The average AHTDF\% of each subset of the data was used as an environmental variable to calculate those parameters. Estimated heritabilities ranged, for both models, from 0.17 to 0.20 (SE 0.02 to 0.03 for the BVM and 0.02 for the RRM). Estimated genetic correlations of fat yield between subsets of the data ranged for both models from 0.83 to 1.00 (SE 0.00 to 0.05 for the BVM and 0.00 to 0.04 for the RRM). Permanent environmental correlations ranged from 0.51 to 1.00 
Table 1. Mean, standard deviation, and range of herd-test-day averages and differences between averages of pairs of consecutive herd-test-days $(\Delta)$ for fat yield, fat percentage, and fat-to-protein ratio.

\begin{tabular}{lrlcc}
\hline Trait & Mean & $\begin{array}{l}\text { Standard } \\
\text { deviation }\end{array}$ & Minimum & Maximum \\
\hline Fat $(\mathrm{kg})$ & 0.77 & 0.13 & 0.37 & 1.21 \\
Fat percentage & 3.87 & 0.33 & 2.18 & 5.48 \\
Fat-to-protein ratio & 1.21 & 0.11 & 0.66 & 1.76 \\
$\Delta$ Fat (kg) & -0.01 & 0.08 & -0.42 & 0.33 \\
$\Delta$ Fat percentage & 0.02 & 0.28 & -1.82 & 1.53 \\
$\Delta$ Fat-to-protein ratio & 0.01 & 0.09 & -0.65 & 0.58 \\
\hline
\end{tabular}

(SE 0.01 to 0.04 ) for the BVM and from 0.29 to 1.00 for the RRM (SE 0.00 to 0.01). Standard errors were higher for the BVM than the RRM in all situations.

The EBV for fat yield estimated with the quadratic random regression on AHTDF\% of 10 sires with most daughters in the data are shown in Figure 3. These 10 sires all had more than 9000 daughters in the data. The EBV are shown for a range of environments with an AHTDF\% between the fifth and 95th percentiles of the data. The course of EBV for fat yield across AHTDF\% differed among those 10 sires (Figure 3), resulting in some reranking of sires across environments.

\section{Estimated Variance Components for Fat Percentage}

The linear RRM was the highest significant order for $\mathrm{MF} \%$. The sire variance for $\mathrm{MF} \%$ as a function of AHTDF\% estimated with a linear RRM is shown in Figure 4. Estimated heritabilities and genetic and per- manent environmental correlations between the different subsets of the data are shown in Table 3. The estimated heritability for MF\% ranged from 0.40 to 0.53 $(\mathrm{SE}=0.03)$ between the fifth and 95th percentile of the data. The estimated genetic and permanent environmental correlations between MF\% expressed in the fifth and 95th percentile of the data were $0.87(\mathrm{SE}=0.02)$ and $-0.05(\mathrm{SE}=0.09)$, respectively.

\section{Estimated Variance Components for MFDLAC and MFDTD}

The linear RRM was the highest significant order for MFDLAC. The sire variance for the linear RRM is shown in Figure 5 as a function of average AHTDF\%. The heritability of MFDLAC was $0.056(\mathrm{SE}=0.015)$ in both the fifth and 95th percentile of the data and had a value of $0.046(\mathrm{SE}=0.008)$ in the average environment. The genetic correlation between MFDLAC ex-

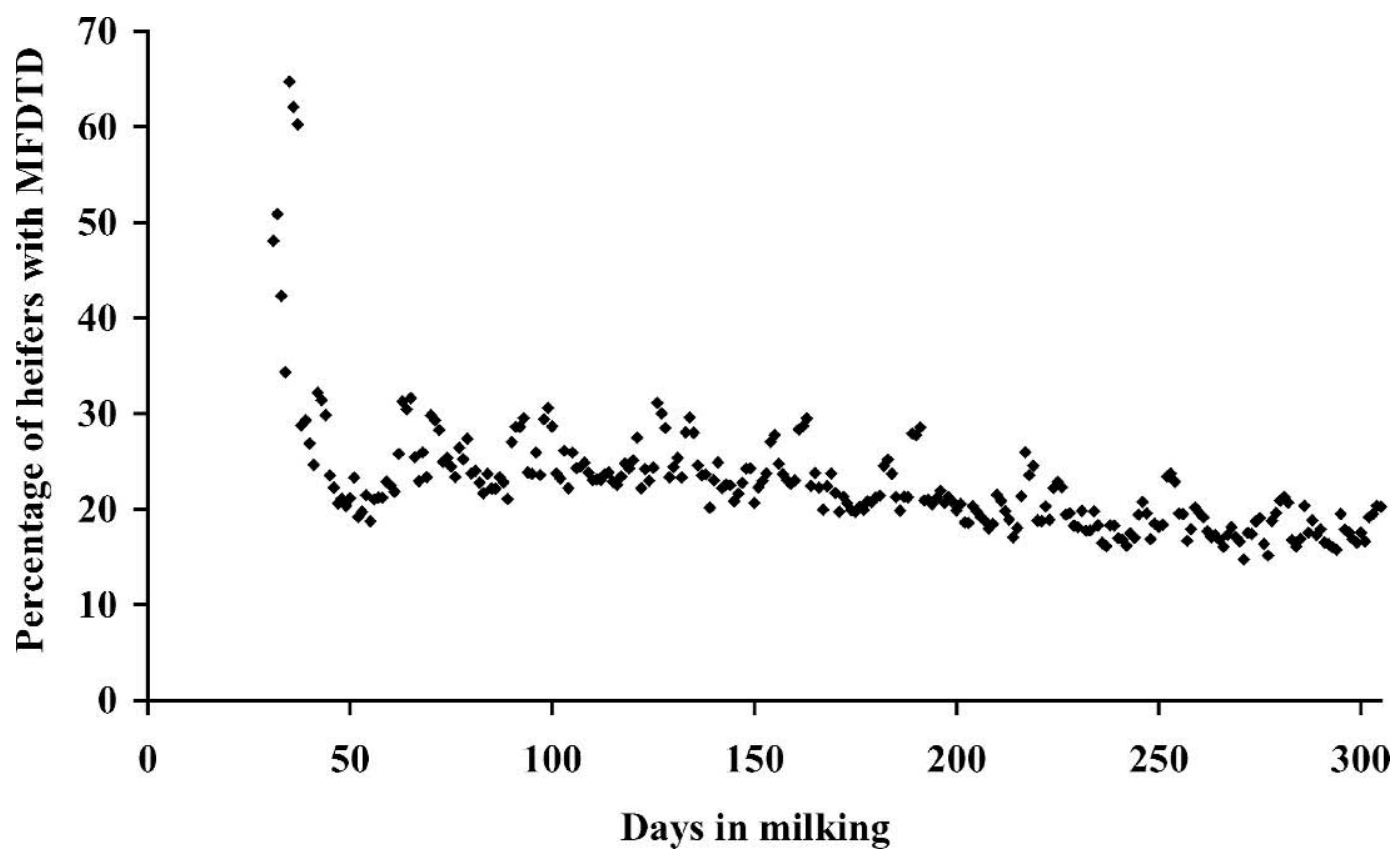

Figure 1. The percentage of heifers showing milk fat depression based on test-days (MFDTD), across days in milking. 


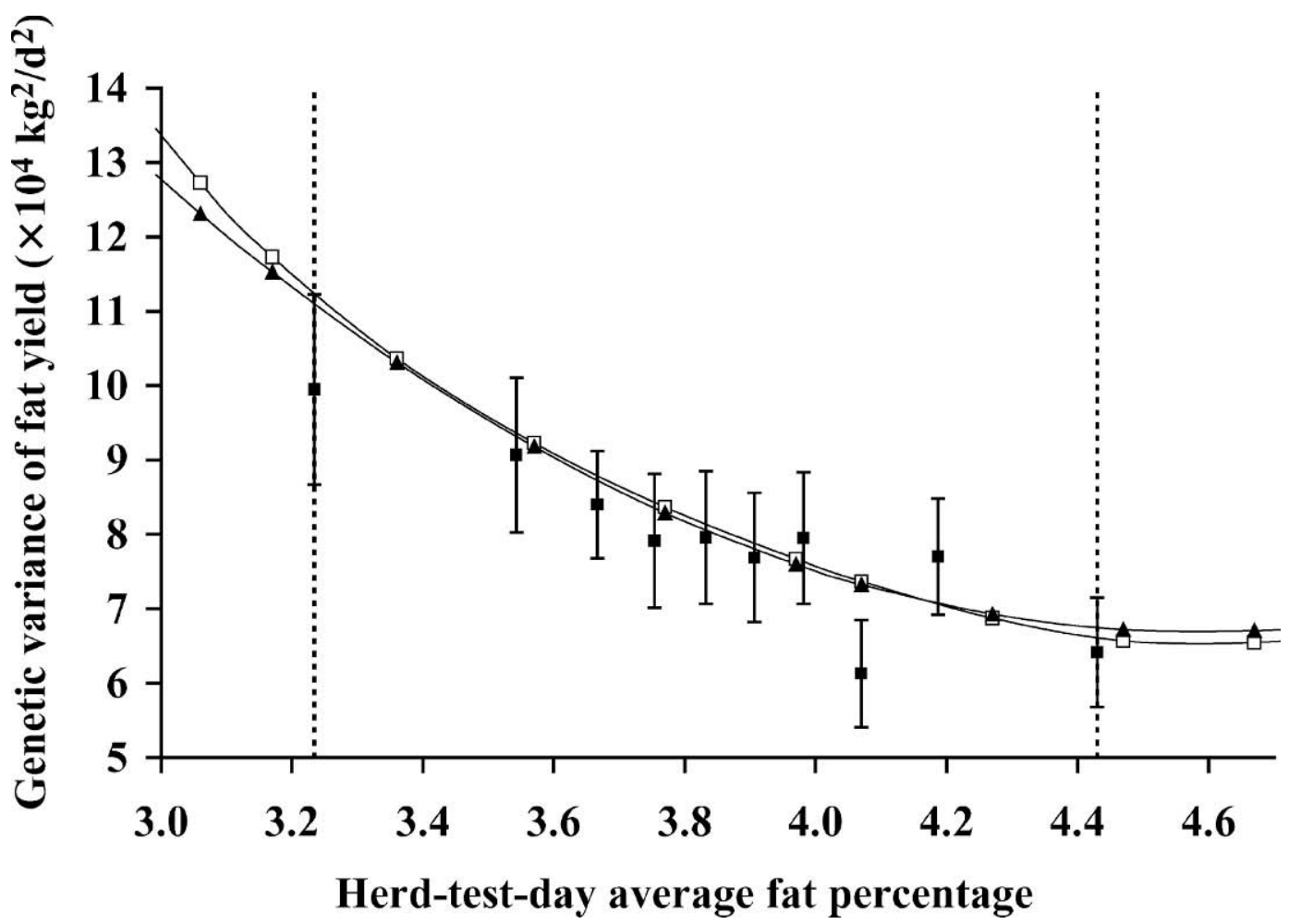

Figure 2. Genetic variances of fat yield $\left(\times 10^{4} \mathrm{~kg}^{2} / \mathrm{d}^{2}\right)$, with environment defined as herd-test-day average fat percentage, estimated with a linear random regression model (RRM) $(\boldsymbol{\Delta})$, a quadratic RRM $(\square)$, and for the different subsets of the data estimated with a bivariate repeatability model (ם). Fifth and 95th percentiles of the data are shown as dotted lines.

pressed in the fifth and 95th percentile of the data was $0.50(\mathrm{SE}=0.20)$.

The linear RRM was the highest significant order for MFDTD (a quadratic order did not converge). The residual variance ranged from 0.056 to $0.008 \%{ }^{2}$ in environments with increasing AHTDF\%. The sire variance is shown in Figure 6 as a function of average AHTDF\%.
The permanent environmental variance across environments was 5 to 11 times as high as the sire variance. The heritability of MFDTD was $0.046(\mathrm{SE}=0.006)$ in the fifth percentile and $0.018(\mathrm{SE}=0.006)$ in the 95th percentile of the data and had a maximum value of $0.053(\mathrm{SE}=0.009)$, within this range of environments. The repeatability of MFDTD had values between 0.53

Table 2. Estimates from the quadratic random regression model for heritabilities ${ }^{1}$ of fat yield (on the diagonal) in 10 subsets of the data defined on increasing average herd-test-day fat percentage (AHTDF\%), and genetic correlations ${ }^{2}$ (above diagonal), and permanent environmental correlations ${ }^{3}$ (under diagonal) between fat yield expressed in the different subsets of the data.

\begin{tabular}{lllllllllll}
\hline AHTDF\% & 3.23 & 3.54 & 3.67 & 3.75 & 3.83 & 3.91 & 3.98 & 4.07 & 4.19 & 4.43 \\
\hline 3.23 & 0.19 & 0.99 & 0.97 & 0.96 & 0.95 & 0.94 & 0.93 & 0.91 & 0.89 & 0.83 \\
3.54 & 0.96 & 0.20 & 1.00 & 0.99 & 0.99 & 0.98 & 0.98 & 0.97 & 0.95 & 0.90 \\
3.67 & 0.92 & 0.99 & 0.19 & 1.00 & 1.00 & 0.99 & 0.99 & 0.98 & 0.96 & 0.92 \\
3.75 & 0.88 & 0.98 & 1.00 & 0.20 & 1.00 & 1.00 & 0.99 & 0.99 & 0.97 & 0.93 \\
3.83 & 0.84 & 0.95 & 0.98 & 1.00 & 0.20 & 1.00 & 1.00 & 0.99 & 0.98 & 0.94 \\
3.91 & 0.79 & 0.92 & 0.96 & 0.99 & 1.00 & 0.19 & 1.00 & 1.00 & 0.99 & 0.95 \\
3.98 & 0.73 & 0.89 & 0.94 & 0.97 & 0.98 & 1.00 & 0.20 & 1.00 & 0.99 & 0.96 \\
4.07 & 0.66 & 0.83 & 0.90 & 0.93 & 0.96 & 0.98 & 0.99 & 0.19 & 1.00 & 0.98 \\
4.19 & 0.54 & 0.75 & 0.82 & 0.87 & 0.91 & 0.94 & 0.97 & 0.99 & 0.18 & 0.99 \\
4.43 & 0.29 & 0.52 & 0.62 & 0.69 & 0.75 & 0.80 & 0.85 & 0.90 & 0.96 & 0.17 \\
\hline
\end{tabular}

${ }^{1} \mathrm{SE}$ of the heritabilities were 0.02 .

${ }^{2} \mathrm{SE}$ of the genetic correlations ranged from 0.00 to 0.04 .

${ }^{3} \mathrm{SE}$ of the permanent environmental correlations ranged from 0.00 to 0.01 . 


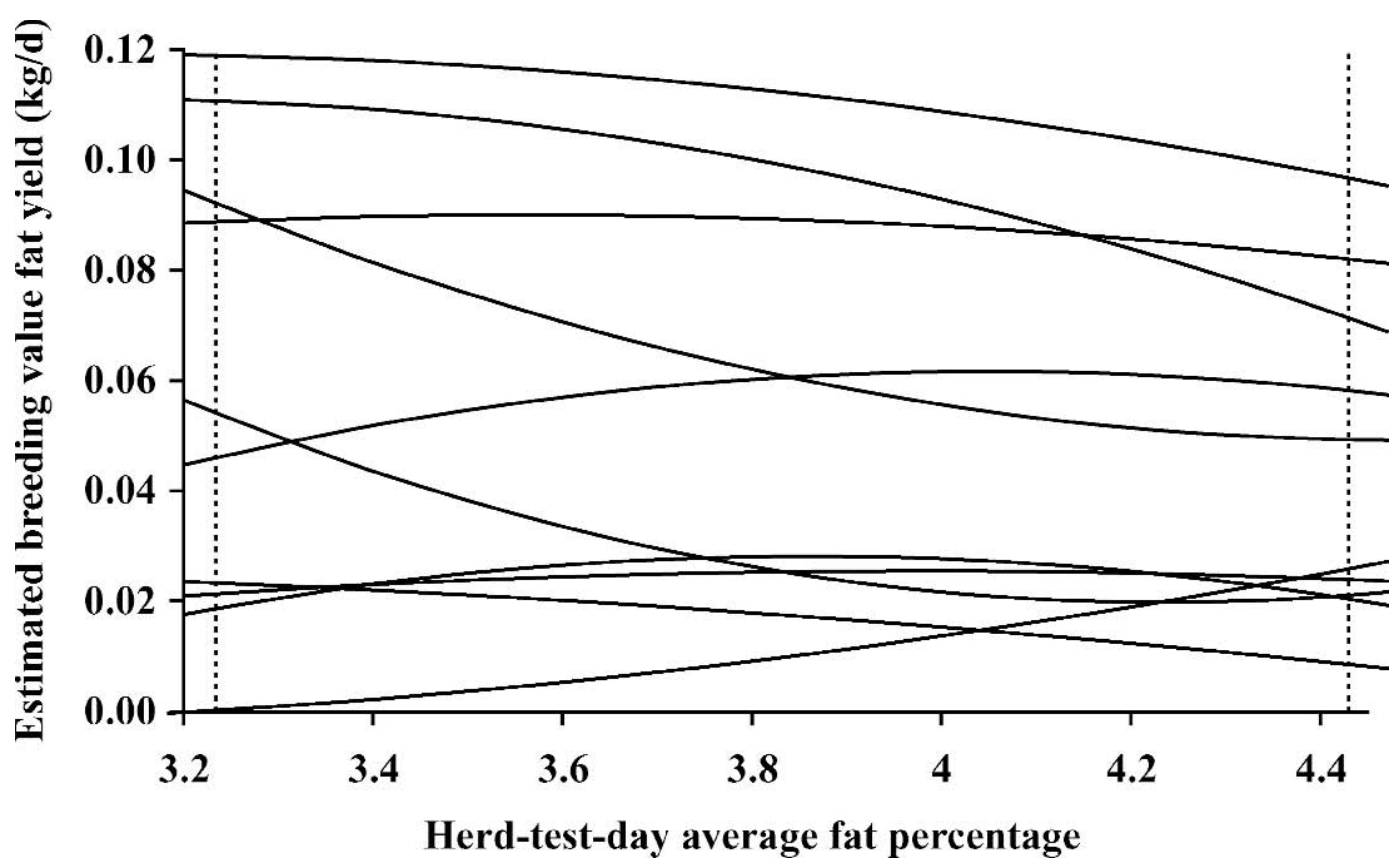

Figure 3. Sire breeding values for fat yield estimated with a quadratic random regression on average herd-test-day fat percentage, of 10 sires with most daughters in the data. Fifth and 95th percentiles of the data are shown as dotted lines.

and $0.75(\mathrm{SE}=0.00)$ in the range of the data between the fifth and 95th percentiles. The genetic and permanent environmental correlations between MFDTD expressed in the fifth and 95th percentile of the data were respectively $0.43(\mathrm{SE}=0.15)$ and $0.65(\mathrm{SE}=0.01)$.

\section{Correlations Between Estimated Breeding Values for the Different Traits}

The EBV for sires with daughters in the data were calculated for the traits MFDLAC, MFDTD, MF\%, and fat yield for environments with values of 3.3 and $4.4 \%$ for AHTDF\%.

Additionally, the changes in EBV for MF\% and fat yield between both environments were calculated as a measure of the environmental sensitivity of the EBV of the sire for MF\% and fat yield. These changes were calculated as EBV at AHTDF\% $=4.4 \%$ minus EBV at AHTDF $\%=3.3 \%$. Correlations between all obtained EBV and changes between EBV are shown in Table 4. The chosen values for AHTDF\% represented approximately the fifth and 95th percentiles of the data for the 4 traits. The EBV for MFDLAC and MFDTD were moderately correlated. The EBV for MFDLAC had small correlations with EBV for MF\% and fat yield. The EBV for MFDTD had moderate positive correlations with EBV for MF\%. The EBV for MFDTD had a positive correlation with EBV for fat yield at AHTDF\% of 3.3\%, but a zero correlation at AHTDF\% of $4.4 \%$.
The EBV for MFDLAC were positively correlated to changes in EBV for MF\% and fat yield. The EBV for MFDTD were negatively correlated to changes in EBV for $\mathrm{MF} \%$ and fat yield, except for the combination of MFDTD at AHTDF\% of $4.4 \%$ and change in EBV for $\mathrm{MF} \%$.

The EBV for MF\% and fat yield were hardly correlated to change in EBV for MF\%, except for the combination of $\mathrm{MF} \%$ and change in fat at AHTDF\% of $4.4 \%$. The EBV for MF\% and fat yield were negatively correlated to change in EBV for fat yield. Changes in EBV for $\mathrm{MF} \%$ and fat yield were positively correlated.

\section{DISCUSSION}

\section{Definition of Environment}

Both $\mathrm{MF} \%$ and fat-to-protein ratio can be used as indicators for MFD (Bargo et al., 2003). Correlations between herd-test-day average $\mathrm{MF} \%$ and fat-to-protein ratio were higher than 0.8 , indicating that use of either MF\% or fat-to-protein ratio as a definition of the environment would yield similar results.

Next to AHTDF\%, the change of AHTDF\% between consecutive test-days was used as definition of environment (results not shown) in the analysis for fat yield and $\mathrm{MF} \%$. Defining the environment by change in AHTDF\% led to less reranking of sires than did defining the environment by $\mathrm{AHTDF} \%$. Change in AHTDF\% was as- 
Table 3. Estimates from the linear random regression model for heritabilities ${ }^{1}$ of fat percentage (on the diagonal) in 10 subsets of the data defined on increasing average herd-test-day fat percentage (AHTDF\%), and genetic correlations ${ }^{2}$ (above diagonal) and permanent environmental correlations ${ }^{3}$ (under diagonal) between fat percentage expressed in the different subsets of the data.

\begin{tabular}{lcccccccccc}
\hline AHTDF\% & 3.23 & 3.54 & 3.67 & 3.75 & 3.83 & 3.91 & 3.98 & 4.07 & 4.19 & 4.43 \\
\hline 3.23 & 0.40 & 0.99 & 0.98 & 0.97 & 0.96 & 0.96 & 0.95 & 0.93 & 0.91 & 0.87 \\
3.54 & 0.93 & 0.48 & 1.00 & 1.00 & 0.99 & 0.99 & 0.98 & 0.97 & 0.96 & 0.93 \\
3.67 & 0.84 & 0.98 & 0.50 & 1.00 & 1.00 & 0.99 & 0.99 & 0.98 & 0.98 & 0.95 \\
3.75 & 0.75 & 0.94 & 0.99 & 0.51 & 1.00 & 1.00 & 1.00 & 0.99 & 0.98 & 0.96 \\
3.83 & 0.65 & 0.88 & 0.96 & 0.99 & 0.52 & 1.00 & 1.00 & 0.99 & 0.99 & 0.97 \\
3.91 & 0.55 & 0.82 & 0.91 & 0.97 & 0.99 & 0.52 & 1.00 & 1.00 & 0.99 & 0.98 \\
3.98 & 0.44 & 0.74 & 0.86 & 0.93 & 0.97 & 0.99 & 0.52 & 1.00 & 1.00 & 0.98 \\
4.07 & 0.32 & 0.65 & 0.78 & 0.87 & 0.93 & 0.97 & 0.99 & 0.51 & 1.00 & 0.99 \\
4.19 & 0.18 & 0.53 & 0.68 & 0.79 & 0.86 & 0.92 & 0.96 & 0.99 & 0.49 & 1.00 \\
4.43 & -0.05 & 0.32 & 0.50 & 0.63 & 0.73 & 0.81 & 0.87 & 0.93 & 0.97 & 0.47 \\
\hline
\end{tabular}

${ }^{1} \mathrm{SE}$ of the heritabilities were 0.03 .

${ }^{2} \mathrm{SE}$ of the genetic correlations ranged from 0.00 to 0.02 .

${ }^{3} \mathrm{SE}$ of the permanent environmental correlations ranged from 0.00 to 0.09 .

signed to the latter of each pair of consecutive herd-testdays that were maximum $70 \mathrm{~d}$ apart. Hence, records of the first herd-test-day in seasonal calving herds had no value for change in AHTDF\%. As it is reported that more than one-third of the cases of acidosis occur in the first month after calving (Gröhn and Bruss, 1990), use of change in AHTDF\% as definition of environment might have resulted in losing relatively a lot of records in early lactation that were subject to MFD.

\section{Environmental Sensitivity of Fat Yield}

Preliminary analyses indicated highest genetic variance of fat yield in environments with low AHTDF\%.
The correlation between herd-test-day average fat yield and AHTDF\% was 0.03, indicating that differences in genetic variance for fat yield across different levels of AHTDF\% could not be explained by the average fat yield for a given herd-test-day. As limited information was available in extreme environments, the BVM was applied to compare results. The application of a multivariate model including all subsets of the data at once would have been theoretically more appealing, but computationally challenging and given the number of traits was likely to result in nonpositive definite variance matrices (Hill and Thompson, 1978). The BVM included only 2 out of 10 subsets of the data at once and, therefore, estimates for genetic and permanent environmen-

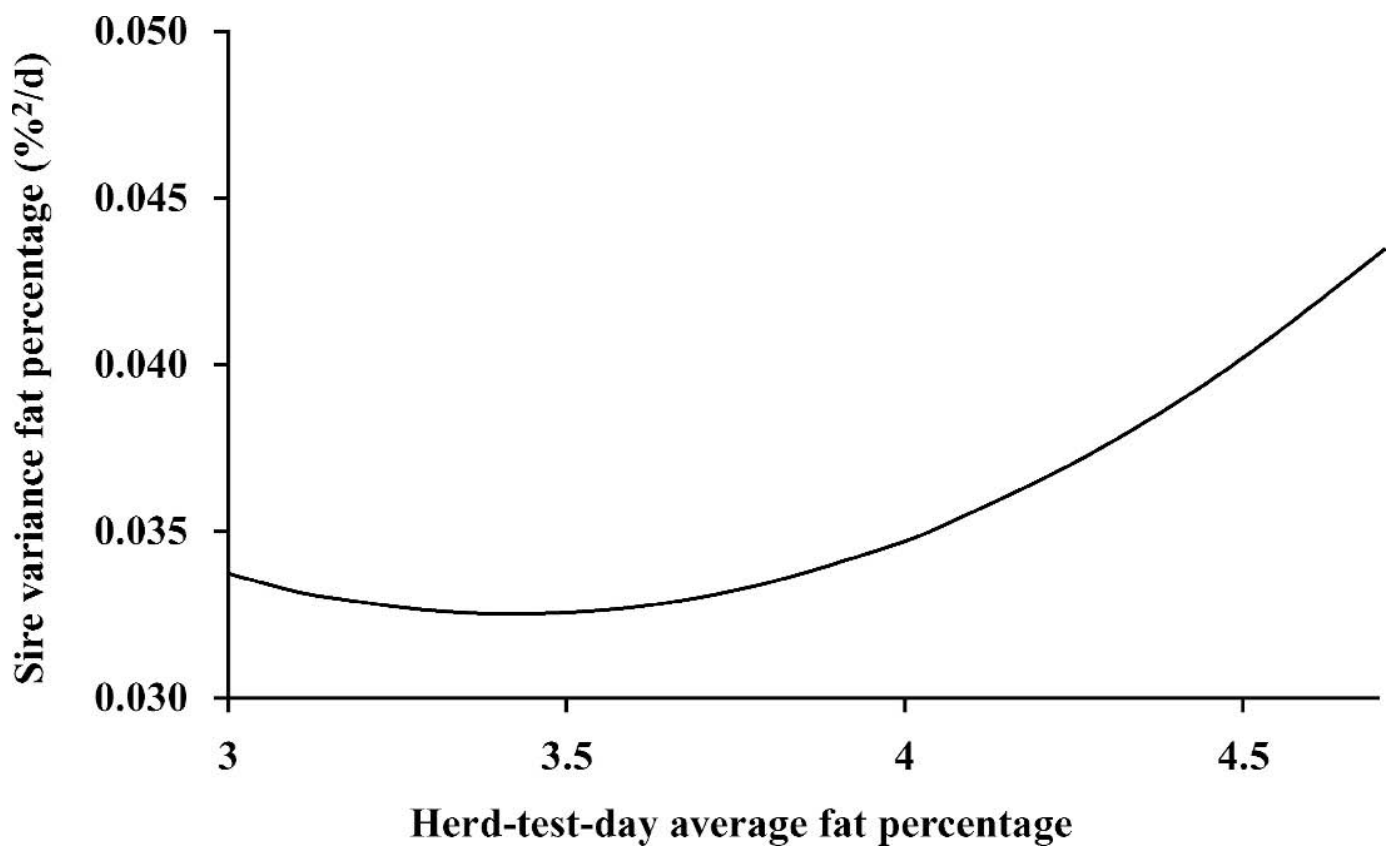

Figure 4. Sire variance $\left(\%^{2} / \mathrm{d}\right)$ for fat percentage estimated with a linear random regression on average herd-test-day fat percentage. 


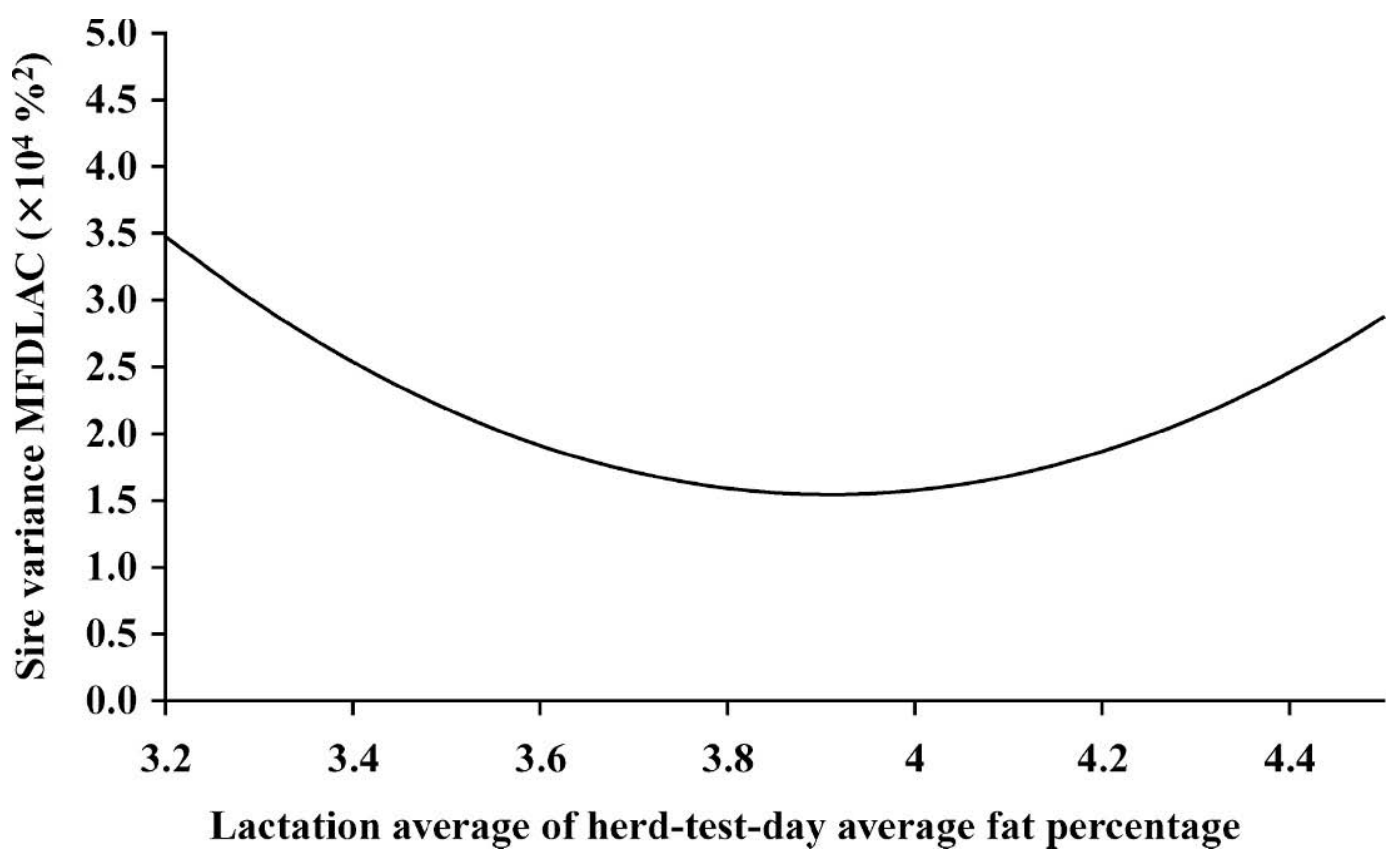

Figure 5. Sire variance $\left(\times 10^{4} \%^{2}\right)$ for milk fat depression defined on a lactation level (MFDLAC) estimated with a linear random regression on lactation average of average herd-test-day fat percentage.

tal correlations between fat yield expressed in different environments were calculated by using only $20 \%$ of the data in the BVM. This is likely to be the reason that, in general, the standard errors of heritabilities and genetic and permanent environmental correlations of fat yield expressed in different environments were lower for the RRM than for the BVM.

The results showed that between the fifth and 95th percentile of the data, the genetic variance for fat yield increased with decreasing AHTDF\%. This increase in genetic variance could be because susceptibility to MFD adds to the variation when AHTDF\% is low. Although there was limited reranking of sires across environments for their EBV of fat yield, the genetic correlations for fat yield expressed in different environments did indicate that fat yield is a different trait in about $10 \%$ of the environments with lowest AHTDF\%. As argued by Hayes et al. (2003), the composition of milk is influenced by DIM, which could lead to confounding between DIM and AHTDF\% in seasonal calving herds. That is, it is possible that the reranking of sires for fat was actually due to differences in the shape of the lactation curve and not to differences in susceptibility to MFD. To exclude this possibility, following Hayes et al. (2003), the correlation between AHTDF\% and DIM was estimated and a RRM with quadratic random regressions for sire and cow on both AHTDF\% and DIM was fitted. The AHTDF\% had a correlation with DIM of -0.15 . An

Table 4. Correlations between estimated sires breeding values calculated for environments with average herd-test-day fat percentage (AHTDF\%) of 3.3\% and 4.4\%, respectively for milk fat depression defined on a lactation level (MFDLAC) or a test-day level (MFDTD), fat percentage (Fat\%), fat yield (Fat), and differences of estimated breeding values for fat percentage $(\Delta \mathrm{Fat} \%)$ and fat yield ( $\Delta \mathrm{Fat}$ ) between the 2 environments (SE ranged from 0.01 to 0.03 ).

\begin{tabular}{lllrrrr}
\hline AHTDF\% & Trait & MFDTD & Fat\% & Fat & $\Delta$ Fat $\%$ & $\Delta$ Fat \\
\hline $3.3 \%$ & MFDLAC & -0.28 & 0.09 & -0.07 & 0.30 & 0.13 \\
& MFDTD & & 0.33 & 0.21 & -0.22 & -0.42 \\
& Fat\% & & 0.51 & 0.07 & -0.48 \\
& Fat & & & -0.08 & -0.72 \\
$4.4 \%$ & MFDLAC & -0.34 & -0.08 & -0.18 & 0.22 & 0.24 \\
& MFDTD & & 0.28 & 0.00 & 0.17 & -0.28 \\
& Fat\% & & & 0.40 & 0.40 & -0.35 \\
& Fat & & & 0.03 & -0.45 \\
& SFat\% & & & & & 0.27 \\
\hline
\end{tabular}




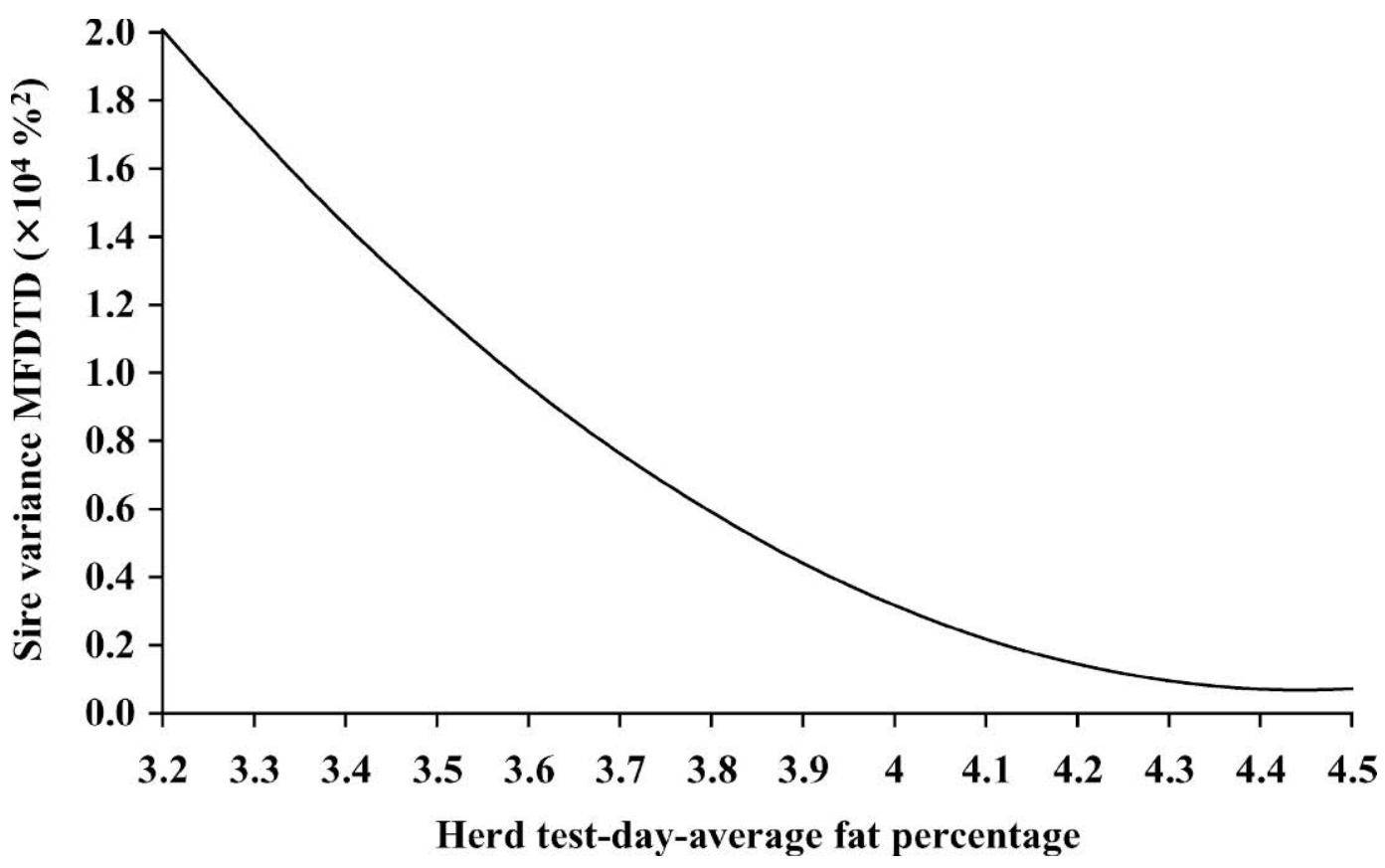

Figure 6. Sire variance $\left(\times 10^{3} \%^{2}\right)$ for milk fat depression defined on a test-day level (MFDTD) estimated with a linear random regression on average herd-test-day fat percentage.

RRM with quadratic random regressions on DIM and AHTDF\% yielded estimated genetic correlations between fat yield expressed in the subsets of the data with the lowest and highest AHTDF\% ranging from 0.85 to 0.90 , across DIM. The corresponding genetic correlation of the RRM with a quadratic random regression on AHTDF\% had a value of 0.83 (Table 2). This suggests that the original estimate of 0.83 is, at most, minimally increased when genetic variation in the shape of the lactation curve is included in the model.

\section{Environmental Sensitivity of Milk Fat Percentage}

The estimated genetic correlation between the fifth and the 95th percentile of the data was higher for MF\% than for fat yield. The estimated permanent environmental correlation between the fifth and the 95th percentile of the data was, however, lower for MF\% than for fat yield, i.e., -0.05 vs. 0.29 . This indicates that both MF\% and fat yield are controlled by different permanent environmental factors in environments with low vs. high $\mathrm{AHTDF} \%$. In other words, cows vary widely for nongenetic reasons in their susceptibility to MFD. The difference in permanent environmental correlations for $\mathrm{MF} \%$ and fat yield is likely a result of different nongenetic factors acting on milk yield in environments with low vs. high AHTDF\%.

\section{Milk Fat Depression Traits}

For MFDTD, 2 test-day records were sufficient to calculate at least one record for an animal, whereas a minimum of 5 test-day records per animal was required for MFDLAC. This explains the difference in number of heifers included in the analysis for MFDLAC and MFDTD. Milk fat percentage was corrected for stage of lactation and age at calving in the calculations of MFDLAC and MFDTD. However, other factors influencing MF\%, such as incomplete milking, could lead to false positive records for MFD. The definitions of MFDLAC and MFDTD imply that there is no individual variation in the shape of the lactation curve for $\mathrm{MF} \%$, and that certain decreases (or changes) in MF\% have the same importance regardless the stage of lactation or MF\% before the change. In the case that an animal has MFD on all test-days within a lactation resulting in comparable reduction of its $\mathrm{MF} \%$ on all test-days, both definitions would fail to identify that the animal has MFD. The current literature provides no indication how the definitions for MFD based on milk recording data could be refined to overcome these limitations.

Both MFD traits tried to capture magnitude and duration of MFD. Arguably, the magnitude of MFD could be thought of as the susceptibility to MFD, and the duration could be thought of as the ability to recover from MFD. Animal experiments in which MFD is stud- 
ied usually reflect the transition to a diet with higher proportions of concentrate and lower proportions of fiber, whereas recovery from MFD typically would be driven by transition to a diet with lower proportions of concentrate and higher proportions of fiber. With regard to this hypothesis, an important question would be to determine if susceptibility to and ability to recover from MFD are strongly correlated. The answer to this question would give more insight into whether MFD can simply be defined on a lactation level, without distinction between magnitude and duration of MFD, or whether MFD should be defined on a test-day level.

In the average environment, i.e., an environment with an AHTDF\% of $3.87 \%$, MFDLAC and MFDTD had heritabilities of 0.045 and 0.042 , respectively. The reliability of an EBV is $r^{2}=n_{e} /\left(n_{e}+\lambda\right)$, where $n_{e}$ is the effective daughter size and $\lambda=\left(4-\mathrm{h}^{2}\right) / \mathrm{h}^{2}$ for a sire model. To obtain a reliability of $60 \%, 132$ effective daughters for MFDLAC and 141 for MFDTD were required for the data set used in our analyses. These figures indicate that active selection based on a trait reflecting MFD is possible.

\section{Correlation Between EBV for the Different Traits}

High susceptibility to MFD should be indicated by low values of MF\% and fat yield at AHTDF\% of 3.3\%, high values for MFDLAC, low values of MFDTD at AHTDF\% of $3.3 \%$ and perhaps AHTDF\% of $4.4 \%$, and low values of change in $\mathrm{MF} \%$ and fat yield.

Correlations among EBV were nearly all in the expected direction but not high. Correlations that were not in the expected direction were correlations of fat yield and change in MF\% with MFDTD at AHTDF\% of $4.4 \%$, which agrees with the idea that MFD plays virtually no role in environments with high AHTDF\% and therefore will hardly influence fat yield and MF\% in those environments. One combination with a moderate correlation (of 0.42) was change in fat yield and MFDTD at AHTDF\% of 3.3\%. These 2 traits are perhaps the best candidates for identifying sires whose daughters are susceptible to MFD. However, before either could be recommended, more evidence is required to support the hypothesis that they identify sires whose daughters are prone to some important outcome such as clinical acidosis or laminitis.

Changes in milk yield and composition between testdays can represent a healthy response to increased nutrition rather than a pathological response such as MFD. One of the challenges in evaluating sires is to distinguish between these 2 possibilities. For this reason, we prefer the use of fat yield to $\mathrm{MF} \%$ as a dependent variable because an increase in milk volume causing a decrease in MF\% is not pathological, but a decrease in fat yield due to increased grain feeding may be.

\section{CONCLUSIONS}

Genetic variation exists between animals in susceptibility to MFD. Data recorded routinely by milk recording agencies can be used to evaluate sires for this trait by using a random regression analysis. Selection for low susceptibility could be based on sires whose daughters show little decline in fat yield between testdays with high and low AHTDF\% or sires whose daughters show a high value of MFDTD when the herd AHTDF\% is low. However, EBV for MFD susceptibility calculated by different methods are not highly correlated and evidence for a genetic correlation with clinical symptoms of MFD would be necessary before advocating the use of any EBV for susceptibility to MFD.

\section{ACKNOWLEDGMENTS}

The Australian Dairy Herd Improvement Scheme is kindly acknowledged for providing the data, and Dairy Australia for financial support of the project. Mario Calus was financially supported by the Dutch Ministry of Agriculture, Nature and Food Quality (Programme 414 "Maatchappelijk verantwoorde veehouderij").

\section{REFERENCES}

Bargo, F., L. D. Muller, J. E. Delahoy, and T. W. Cassidy. 2002. Milk response to concentrate supplementation of high producing dairy cows grazing at two pasture allowances. J. Dairy Sci. 85:17771792.

Bargo, F., L. D. Muller, E. S. Kolver, and J. E. Delahoy. 2003. Invited review: Production and digestion of supplemented dairy cows on pasture. J. Dairy Sci. 86:1-42.

Calus, M. P. L., and R. F. Veerkamp. 2003. Estimation of environmental sensitivity of genetic merit for milk production traits using a random regression model. J. Dairy Sci. 86:3756-3764.

Dalley, D. 2002. Overcoming decreased milk solids production for Gippsland dairy herds in late winter/spring. Natural Resources and Environment, Agriculture Victoria Ellinbank, Australia.

De Vries, M. J., and R. F. Veerkamp. 2000. Energy balance of dairy cattle in relation to milk production variables and fertility. J. Dairy Sci. 83:62-69.

Gaynor, P. J., R. A. Erdman, B. B. Teter, J. Sampugna, A. V. Capuco, D. R. Waldo, and M. Hamosh. 1994. Milk fat yield and composition during abomasal infusion of cis or trans octadecenoates in Holstein cows. J. Dairy Sci. 77:157-165.

Gilmour, A. R., B. J. Gogel, B. R. Cullis, S. J. Welham, and R. Thompson. 2002. ASREML User Guide Release 1.0. VSN International Ltd., Hemel Hempstead, UK.

Griinari, J. M., D. A. Dwyer, M. A. McGuire, D. E. Bauman, D. L. Palmquist, and K. V. Nurmela. 1998. Trans-octadecenoic acids and milk fat depression in lactating dairy cows. J. Dairy Sci. 81:1251-1261.

Gröhn, Y. T., and M. L. Bruss. 1990. Effect of diseases, production, and season on traumatic reticuloperitonitis and ruminal acidosis in dairy cattle. J. Dairy Sci. 73:2355-2363.

Gröhn, Y. T., H. N. Erb, C. E. McCulloch, and H. S. Saloniemi. 1989. Epidemiology of metabolic disorders in dairy cattle: Association 
among host characteristics, disease, and production. J. Dairy Sci. 72:1876-1885.

Hayes, B. J., M. Carrick, P. Bowman, and M. E. Goddard. 2003. Genotype x environment interaction for milk production of daughters of Australian dairy sires from test-day records. J. Dairy Sci. 86:3736-3744.

Hill, W. G., and R. Thompson. 1978. Probabilities of non-positive definite between-group or genetic covariance matrices. Biometrics 34:429-439.

Kennelly, J. J., B. Robinson, and G. R. Khorasani. 1999. Influence of carbohydrate source and buffer on rumen fermentation characteristics, milk yield, and milk composition in early-lactation Holstein cows. J. Dairy Sci. 82:2486-2496.

Kirkpatrick, M., D. Lofsvold, and M. Bulmer. 1990. Analysis of the inheritance, selection and evolution of growth trajectories. Genetics 124:979-993.

Kolmodin, R., E. Strandberg, P. Madsen, J. Jensen, and H. Jorjani. 2002. Genotype by environment interaction in Nordic dairy cattle studied using reaction norms. Acta Agric. Scand. A Anim. Sci. $52: 11-24$.

Loeffler, S. H., M. J. de Vries, and Y. H. Schukken. 1999. The effects of time of disease occurrence, milk yield, and body condition on fertility of dairy cows. J. Dairy Sci. 82:2589-2604.

Nocek, J. E. 1997. Bovine acidosis: Implications on laminitis. J. Dairy Sci. 80:1005-1028.

Stockdale, C. R., A. Callaghan, and T. E. Trigg. 1987. Feeding high energy supplements to pasture-fed dairy cows. Effect of stage-oflactation and level of supplement. Aust. J. Agric. Res. 38:927-940.

Sutton, J. D. 1989. Altering milk composition by feeding. J. Dairy Sci. 72:2801-2814.

Veerkamp, R. F., and M. E. Goddard. 1998. Covariance functions across herd production levels for test-day records on milk, fat, and protein yields. J. Dairy Sci. 81:1690-1701.

Windig, J. J., M. P. L. Calus, G. de Jong, and R. F. Veerkamp. Herd variation in the association between somatic cell count patterns and milk production prior to mastitis. Livest. Prod. Sci. (accepted) 